IBIMA Publishing

Advances in Cancer Research \& Treatment

http://www.ibimapublishing.com/journals/ACRT/acrt.html

Vol. 2013 (2013), Article ID 442049, 11 pages

DOI: $10.5171 / 2013.442049$

Research Article

\title{
Basal Cell Carcinoma. Treatment with Carbon Dioxide Laser Vaporization
}

\author{
Jesús del Pozo and Laura Rosende \\ Unit of laser, Department of Dermatology, CHU A Coruña, Spain
}

Correspondence should be addressed to: Jesús del Pozo; jesus.del.pozo.losada@sergas.es

Received 21 October 2012; Accepted 8 November 2012; Published 19 June 2013

Academic Editor: Eleni Drakaki

Copyright (C) 2013 Jesús del Pozo and Laura Rosende. Distributed under Creative Commons CC-BY 3.0

\begin{abstract}
Background: Basal cell carcinoma (BCC) is the most common malignant epidermal tumor of the skin. Several treatment options for BCC have been described including ablative and other laser systems.
\end{abstract}

Objectives: To evaluate the efficacy of carbon dioxide (CO2) laser vaporization in the treatment of superficial and nodular BCC.

Method of treatment: All treatments were performed with local anaesthesia. In the first pass, superpulsed and focused mode, with a power density of 5 to $10 \mathrm{~W} / \mathrm{cm} 2$, to eliminate the superficial layer was used. When the necrotic debris was eliminated a flaming red surface appeared with central bleeding surrounded by a pink peripheral area that corresponds to unaffected skin. In the next passes, this area must disappear.

Results: In all patients BCCs are adequately removed after treatment. After a year of follow-up no recurrences were observed. Our patients presented three secondary effects: persistent and transitory erythema, hypopigmented areas and textural alterations.

Discussion: $\mathrm{CO} 2$ vaporization shows some advantages in the treatment of BCC, in patients with numerous and large lesions, it had a highly precise and confined tissue damage.

The treatment offers a virtually bloodless intraoperative field, the postoperative evolution by a minimal postoperative pain and it is easy to repeat the treatment if necessary.

Conclusion: "97\% long-term cure rate in patients with BCC treated with the $\mathrm{CO} 2$ laser can be achieved." Although surgical excision remains the treatment of choice for basal cell carcinoma, CO2 laser ablation offers many advantages in specific situations."

Keywords: Basal cell carcinoma, Carbon dioxide, laser vaporization.

Cite this Article as: Jesús del Pozo and Laura Rosende (2013), "Basal Cell Carcinoma. Treatment with Carbon Dioxide Laser Vaporization," Advances in Cancer Research \& Treatment, Vol. 2013 (2013), Article ID 442049, DOI: 10.5171/2013. 442049 


\section{Introduction}

Basal cell carcinoma (BCC) is the most common malignant epidermal tumour of the skin that's derived from the basal layer of the epidermis. The tumour infiltrates tissues in a three-dimensional fashion (Braun et al 2005) usually with a slow growing, and metastases are extremely rare (Lo et al 1991). Tumor-related morbidity results from local tissue invasion and destruction that might be very important in some areas such as the face.

BCCs vary greatly in appearance and several clinical types had been described including nodular, cystic, superficial, sclerosing, keratotic, and pigmented.

Dermatologists usually perform clinical diagnosis of BCC. Diagnostic accuracy is enhanced by dermoscopy (Felder et al 2006) and confirmed by histopathological examination. Biopsy is also indicated when clinical doubt exists or when the histological subtype of BCC may influence treatment selection and prognosis (Telfer et al 2008).

Histological subtypes are mainly three: nodular, expansive and infiltrative. The most important form is the infiltrative pattern that usually corresponds to a sclerosing clinical pattern because it has the worst prognosis.

An important histopathological characteristic of BCC, like in other tumours, is the neoangiogenesis process, crucial requirement for tumour nutrition and growth, manifested as an increased in the number of blood vessels in the tumour. BCC contains a basket-like capillary plexus interwoven throughout the tumour bed, with many abnormal blood vessels with luminal diameters of $20 \mu \mathrm{m}$ and more (Van der Geer et al 2009). This vascular component is used as a target in the treatment of BCC with some specific vascular lasers.

Several treatment options for basal cell carcinoma have been described including surgical excision (Walker et al 2006), curettage (Barlow et al 2006) and cautery
(Spiller et al 1984), cryotherapy (Mallon et al 1996, Kokoszka 2003), radiotherapy (AlOthman 2001), photodynamic therapy (Star et al 2006, Chapas et al 2006, Brathen et al 2007), micrographic surgery (Bieley et al 1992, Rowe et al 1989)), ablative laser (Goldman and Wilson 1964, MacGuff 1966, Goldman et al 1968, Adams and Price 1979, Wheeland et al 1987, Fairhurst et al 1992, Grobbelaar et al 1997, Krunic et al 1998, Humpreys et al 1998, Horlock et al 2000, Nouri et al 2002, Campolmi et al 2002, Robinson et al 2003, and Smuckler et al 2008), other laser systems (El-Tonsy et al 2004, Moskalik et al 2009, Allison et al 2003, Campolmi et al 2008, Shah et al 2009, Konnikov et al 2011, Ibrahimi et al 2011), topical treatment with 5-fluorouracil and immunomodulators, such as imiquimod (Kagy and Amonette 2000, Schulze et al 2005) and intralesional agents as interferon (Greenway et al 1986).

The selection of treatment in each patient depends on several factors, such as some definable prognostic factors (Telfer et al 2008), that classify these tumours with low or high risk:

1. Tumour size (increasing size confers higher risk of recurrence)

2. Tumour site (lesions on the central face, especially around the eyes, nose, lips and ears, are at higher risk of recurrence)

3. Definition of clinical margins (poorly defined lesions are at higher risk of recurrence)

4. Histological subtype (certain subtypes confer higher risk of recurrence)

5. Histological features of aggression (perineural and / or perivascular involvement confers higher risk of recurrence)

6. Failure of previous treatment (recurrent lesions are at higher risk of further recurrence)

7. Immunosuppression (possibly confers increased risk of recurrence) 
Surgery and radiotherapy (RT) remains the treatments of choice for the majority of high-risk lesions, nevertheless, with the recent development of more effective topical and nonsurgical therapies, the treatment options for many low-risk lesions are extended (Bath-Hextall et al 2007).

Patient specific factors, like general fitness, coexisting serious medical conditions, and the use of antiplatelet or anticoagulant medication may also influence the choice of treatment. A conservative approach to asymptomatic, low-risk lesions will prevent treatment causing more problems than the lesion itself. Even when dealing with highrisk BCC, aggressive management may be inappropriate for certain patients, especially the very elderly or those in poor general health, when a palliative rather than a curative treatment regimen may be in the best interests of the patient (Telfer et al 2008).

Finally, factors including patient choice, local availability of specialized services, together with the experience and preferences of the involved specialist may influence treatment selection.

In this manner, there are some instances when an easy destructive modality as carbon dioxide laser vaporization may be preferred:

1. In patients with numerous tumours or basal cell carcinomas of large size,

2. In locations with difficult surgical solution, such as inferior lower lip,

3. In patients with basal cell nevus syndrome or immunosuppression who may develop literally dozens to hundreds of tumours,

4. In elderly patients with multiple comorbidities, who take multiple medications which sometimes include anticoagulants, may not be ideal surgical candidates.

Therefore, we present the carbon dioxide laser vaporization as a good alternative treatment of BCC in selected cases and instances.

\section{Method of Treatment}

The treatment of BCC with carbon dioxide laser was performed under local anaesthesia of $2 \%$ mepivacaine without epinephrine. An adequate informed consent signed by the patient is obtained before performing the treatment. Usually several laser passes were necessary in order to eliminate all tumoral tissues. The number of passes of laser required depends on the type of BCC and the time of evolution.

The superpulsed mode of carbon dioxide laser emits high fluence (energy density) with short pulse time of exposition, providing a good degree of vaporization with minimal surrounding thermal tissue damage.

It was not difficult to delimitate the lesion by experienced doctors. The researchers carried out another pass after the tumoral tissue has been completely removed with a security margin of $5 \mathrm{~mm}$ around the suspected tissue. All the cellular detritus might be retired in order to achieve a good healing and if possible, a good cosmetic result. A cure with topical antibiotic ointment until the total resolution of the lesion was prescribed.

In the first pass, the researchers used superpulsed and focused mode (beam diameter $1 \mathrm{~mm}$ ), with a power density of 5 to $10 \mathrm{~W} / \mathrm{cm} 2$, to eliminate the superficial layer. They used a focused mode in the first pass because with this mode, the deep penetration of the carbon dioxide laser is higher, the elimination of the tumoral tissue is more effective, and the possibility of recurrence is reduced. After this pass, the partially desiccated tissue was manually removed with a saline-soaked gauze. When the necrotic debris was eliminated, a flaming red surface appears with central bleeding surrounded by a pink peripheral area that corresponds to unaffected skin appears. In the next passes, this area must disappear because it 
represents tissue infiltrated by tumour, according to the neoangiogenic induction produced by BCC. The flaming red surface is the guide to the surgeon. The decision of number of passes required to eliminate the tumour was made on the histologic type and the time of evolution of the lesion. When a superficial basal cell carcinoma was treated, usually only two of three passes were necessary, except in lesions with several years of evolution. When the treatment was performed in nodular BCC, five or six passes were considered to be necessary, so a residual scar after healing was expected.
After laser treatment, topical antibiotic ointment was applied to the wound, and covered with a dressing. A daily wound cleaning of the treated area with mild soap and water, followed by application of antibiotic ointment for a period of 2 weeks, was indicated. A new physician evaluation was made after 6 weeks of treatment.

\section{Results}

This paper presents some cases of BCC treated with $\mathrm{CO} 2$ laser vaporization in order to illustrate this treatment modality.

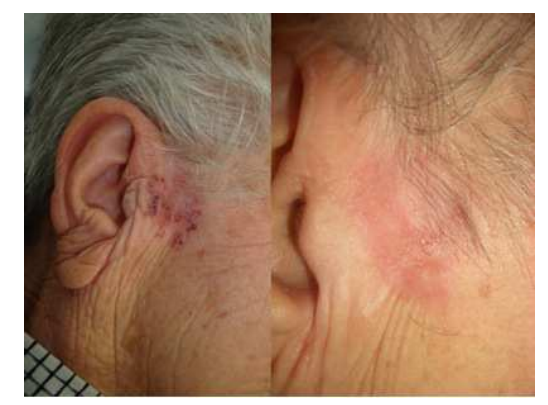

In Figure 1, a BCC with Several Years of Evolution on Preauricular Area was Presented. If Surgical Treatment was Performed, a Flap or Graft Should be Necessary. The Researchers Performed a Vaporization of the Lesion with Carbon Dioxide Laser, the Cosmetic Result was Excellent Except by a Slight Erythema of Treated Area, and No Recurrence was Observed after one Year of Follow-Up. 

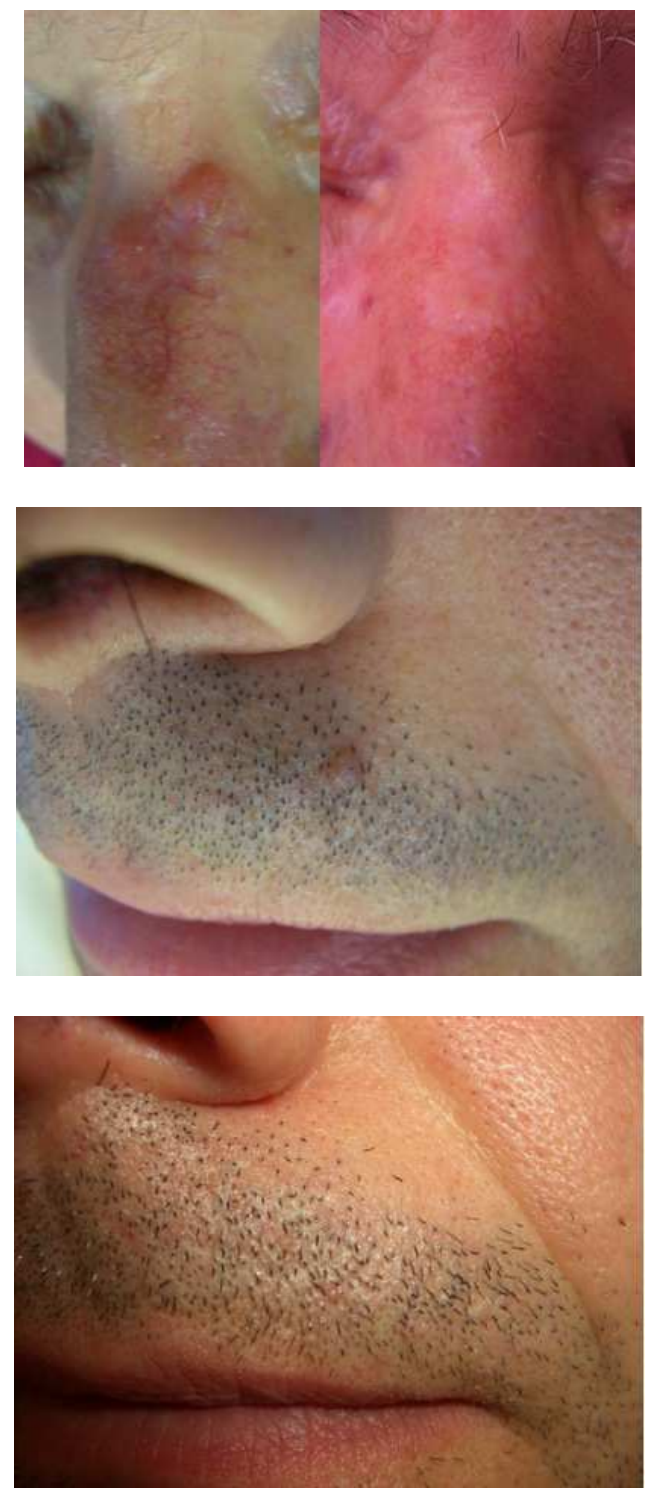

In Figure 2, A Nodular BCC in the Dorsum of the Nose was Treated with Carbon Dioxide Laser Vaporization. Besides Residual Hypopigmentation, the Cosmetic Result of Carbon Dioxide Laser Treatment was Excellent. Figures 3 and 4 Shows Another Nodular BCC before and after Treatment with Carbon Dioxide Laser Vaporization. In this Case, the Cosmetic Result was Excellent. 

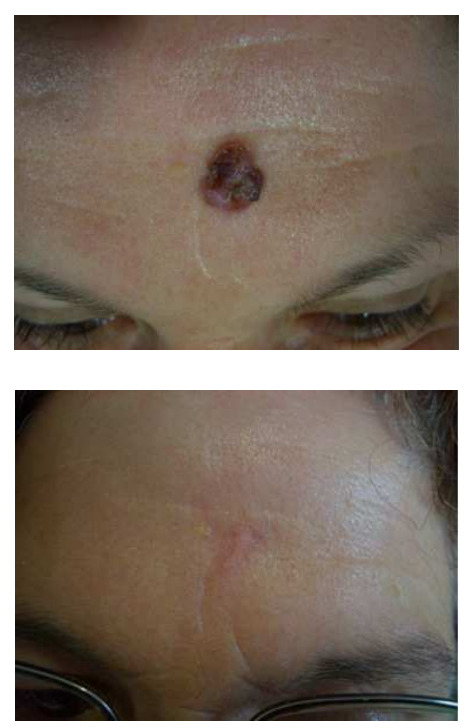

Figure 5 Represents a Frontal Nodular and Pigmented BCC. after Treatment, a Residual Depressed Scar Appeared (Figure 6). In this Case, more than 5 Passes of Treatment were Necessary to Completely Remove the Lesion.
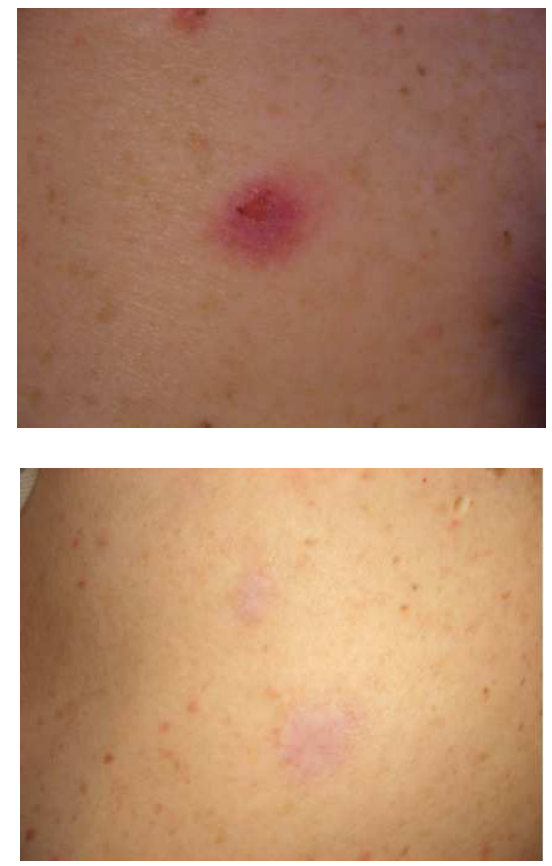

Figures 7 and 8 Shows a Superficial BCC before and after Carbon Dioxide Laser Vaporization. A Hypopigmented Area Appeared after the Treatment but it Tended to Spontaneously Fade over Time. Although Hypopigmentation Completely Resolves with Time, in Some Cases it was Permanent Albeit Improved. 


\section{Discussion}

Several laser therapy options for the treatment of basal cell carcinoma have been described including carbon dioxide laser (Adams and Price 1979, Wheeland et al 1987, Fairhurst et al 1992, Grobbelaar et al 1997, Krunic et al 1998, Humpreys et al 1998, Horlock et al 2000, Nouri et al 2002, Campolmi et al 2002, Robinson et al 2003), erbium:YAG laser (Smuckler et al 2008), Nd:YAG laser (El-Tonsy et al 2004, Moskalik et al 2009), pulsed dye laser (Allison et al 2003, Campolmi et al 2008, Shah et al 2009, Konnikov et al 2011), alexandrite laser (Ibrahimi et al 2011) and photodynamic therapy (Star et al 2006, Chapas et al 2006, Brathen et al 2007).

With non-ablative lasers as pulsed dye laser (Allison et al 2003, Campolmi et al 2008, Shah et al 2009, Konnikov et al 2011), Nd:YAG laser (El-Tonsy et al 2004, Moskalik et al 2009) and alexandrite laser (Ibrahimi et al 2011), the treatment of BCC is based on the angiogenic component presented in this tumour. Usually, several sessions of treatment should be performed in order to eliminate the lesion. The elimination of deep lesions was not achieved by these techniques due to the limited depth of penetration of these lasers.

With ablative lasers as carbon dioxide laser (Adams and Price 1979, Wheeland et al 1987, Fairhurst et al 1992, Grobbelaar et al 1997, Krunic et al 1998, Humpreys et al 1998, Horlock et al 2000, Nouri et al 2002, Campolmi et al 2002, Robinson et al 2003) and erbium:YAG laser (Smuckler et al 2008), the angiogenic component being a guide to the surgeon that indicates the elimination of the tumour, the lesion can be vaporized as deep as possible with the increase of the passes number. The ability to vaporize of carbon dioxide laser is higher than erbium:YAG laser and the majority of studies concerning the treatment of BCC with ablative lasers was performed with $\mathrm{CO} 2$ laser.

CO2 laser treatments treatments might be used in the treatment of superficial or nodular BCC. In morpheiphorm or infiltrative cases, these destructive techniques were not indicated because they do not allow histopathological study of the lesion margins. It is possible save a minimal amount of tissue previous to laser vaporization for histopathological confirmation of the diagnosis, but the absence of tumour infiltration in the lesion margins cannot be defined.

Carbon dioxide laser treatment of BCC have been largely described several years ago but few studies have been performed and they showed very different results (Adams and Price 1979, Wheeland et al 1987, Humpreys et al 1998, Horlock et al 2000, Campolmi et al 2002).

Adams and Price (1979) reported the use of the carbon dioxide laser to treat BCC in 1979 using a continuous output laser. They treated 25 BCCs with a single nonoverlapping pass and performed postoperative histologic analyses with persistence of the tumour on treated skin in $50 \%$ of biopsies.

Wheeland et al (1987) treated 370 superficial BCCs with one to three passes of a continuous mode $\mathrm{CO} 2$ laser in conjunction with curettage between passes. They followed patients clinically for a period of 6 to 65 months (mean 19.9 months) and found no evidence of recurrence in the treated tumours. Although hypertrophic scarring occurred in $5 \%$ of patients, the authors emphasize the advantages of laser treatment, including minimal postoperative pain, rapid healing and superior cosmetic results.

Horlock et al (2000) treated 21 superficial, 28 nodular and 2 infiltrative basal cell carcinomas with multiple passes until clinical resolution was obtained and subsequently treated with two additional passes. Nodular tumours less than $10 \mathrm{~mm}$ diameter were completely ablated if they were vaporize to a depth of the lower dermis or deeper, whereas large nodular tumors greater than $10 \mathrm{~mm}$ had a high incomplete ablation rate. The study did not include long-term clinical evaluations of the patients. 
Iyer S et al (2004) performed a retrospective review of patients with both nodular and superficial BCCs treated with the UltraPulse $\mathrm{CO} 2$ laser. Of the 61 tumours treated, clinical recurrence was observed in two cases (3.2\%). Adverse effects included significant hypertrophic scarring in one patient and hypopigmentation in the other.

Destruction of superficial and nodular BCC may be accomplished successfully and safely with the UltraPulse CO2 laser with a cure rate of $97 \%$ (Jung et al 2011).

The main secondary effects after CO2 laser treatment were persistent erythema, hypopigmented areas and textural alterations. Persistent erythema appeared in all cases when important areas were treated. It is a vascular temporal reaction induced by the healing tissue. Hypopigmented areas resulted from the elimination of the melanocytes during laser treatment. In the healing process, the pigmentation of the treated area was recovered by the peripheral or follicular melanocytes, but in some cases it was not possible and this secondary effect was permanent. Textural alterations appeared when a deep vaporization was performed and medium or deep dermis was destroyed.

Superficial and nodular BCC are usually the most adequate types to be treated with carbon dioxide laser vaporization, with excellent results. Sclerodermiform or morpheiphorm variants of basal cell carcinoma not been due treated with this modality.

Ultra-Pulse $\mathrm{CO} 2$ ablation confers the following advantages in:

1. In patients with numerous and large lesions, CO2 laser had minimal postoperative morbidity and shorter postoperative healing time,

2. The highly precise and confined tissue damage and therefore potentially better cosmesis,

3. The treatment therefore offers a virtually bloodless intraoperative field,
4. The postoperative evolution by a minimal postoperative pain,

5. The follow-up it is easy to repeat the treatment if it is necessary.

The main limitations of carbon dioxide laser vaporization of basal cell carcinomas are the following:

1. The disponibility and the price of the treatment,

2. The absence of histopathological control of the treatment,

3. The experience of the surgeon who performs the treatment,

4. The presence of secondary effects, essentially scarring and hypopigmentation. These secondary effects are more frequent in nodular cases of basal cell carcinoma because of the fact that more deep treatment is necessary to clear the tumour.

At this moment the evidence level is: Carbon dioxide laser ablation may be effective in the treatment of low-risk BCC. (Strength of recommendation $\mathrm{C}$, quality of evidence III). Nevertheless, the results show that carbon dioxide laser might be an effective treatment with low recurrences. More studies are necessary in order to increase the evidence level.

\section{Conclusion}

"97\% long-term cure rate in patients with basal carcinoma treated with the UltraPulse $\mathrm{CO} 2$ laser can be achieved. Although surgical excision remains the treatment of choice for basal cell carcinoma, CO2 laser ablation offers many advantages in specific situations as previously discussed."

\section{References}

Adams, E. L. \& Price, N. M. (1979). 'Treatment of Basal Cell Carcinoma with a Carbon Dioxide Laser,'J Dermatol Surg Oncol; 5: 803-6. 
Allison, K. P., Kiernan, M. N., Waters, R. A. \& Clement, R. M. (2003). "Pulsed Dye Laser Treatment of Superficial Basal Cell Carcinoma: Realistic or Not?," Lasers in Medical Science; 18: 125-6.

Al-Othman, M. O. F., Mendenhall, W. M. \& Amdurm, R. J. (2001). "Radiotherapy Alone for Clinical T4 Skin Carcinoma of the Head and Neck with Surgery Reserved for Salvage," American Journal of Otolaryngology (2001); 22: 387-90.

Barlow, J. O., Zalla, M. J., Kyle, A., et al (2006). "Treatment of Basal Cell Carcinoma with Curettage Alone," Journal of the American Academy of Dermatology; 54: 1039-45.

Bath-Hextall, F., Perkins, W., Bong, J. \& Williams, H. C. (2007). "Interventions for Basal Cell Carcinoma of the Skin," Cochrane Database of Systematic Reviews; 1:CD003412.

Bieley, H. C., Kirsner, R. S., Reyes, B. \& Garland, L. D. (1992). "The Use of Mohs Micrographic Surgery for Determination of Residual Tumor in Incompletely Excised Basal Cell Carcinoma," Journal of the American Academy of Dermatology; 26: 754-6.

Braathen, L. R., Szeimies, R.- M., BassetSeguin, N., et al (2007). "Guidelines on the Use of Photodynamic Therapy for Nonmelanoma Skin Cancer. An International Consensus," Journal of the American Academy of Dermatology; 56:125-43.

Braun, R. P., Klumb, F., Bondon, D., et al (2005). "Three-Dimensional Reconstruction of Basal Cell Carcinomas," Dermatologic Surgery; 31: 562-6.

Campolmi, P., Brazzini, B., Urso, C., Ghersetich, I., Mavilia, L., Hercogova, J. \& Lotti, T. (2002). "Superpulsed CO2 Laser Treatment of Basal Cell Carcinoma with Intraoperatory Histopathologic and Cytologic Examination," Dermatologic Surgery; 28: 909-11.
Campolmi, P., Troiano, M., Bonan, P., Cannarozzo, G. \& Lotti, T. (2008). "Vascular Based Non Conventional Dye Laser Treatment for Basal Cell Carcinoma," Dermatologic Therapy; 21: 402-5.

Chapas, A. M. \& Gilchrest, B. A. (2006). "Broad Area Photodynamic Therapy for Treatment of Multiple Basal Cell Carcinomas in a Patient with Nevoid Basal Cell Carcinoma Syndrome," Journal of drugs in dermatology; 5(2 Suppl): 3-5.

El-Tonsy. M. H., El-Domyati, M. M., El-Sawy, A. E., El-Din, W. H., Anbar, Tel-D. \& Raouf, H. A. (2004). "Continuous-Wave Nd:Yag Laser Hyperthermia: A Successful Modality in Treatment of Basal Cell Carcinoma," Dermatology Online Journal; 15; 10(2): 3.

Fairhurst, M. V., Roenigk, R. K. \& Brodland, D. G. (1992). "Carbon Dioxide Laser Surgery for Skin Disease," Mayo Clinic Proceedings; 67: 49-58.

Felder, S., Rabinovitz, H. \& Oliviero, M. \& Kopf, A. (2006). "Dermoscopic Differentiation of a Superficial Basal Cell Carcinoma and Squamous Cell Carcinoma in Situ," Dermatologic Surgery; 32: 423-5.

Greenway, N. T., Cornell, R. C., Tanner, D. J., et al (1986). "Treatment of Basal Cell Carcinoma with Intralesional Interferón," Journal of the American Academy of Dermatology; 15: 437-43.

Grobbelaar, A. O., Horlock, N. \& Gault, D. T. (1997). “Gorlin's Syndrome: The Role Carbon Dioxide Laser in Patient Management," Annals of Plastic Surgery; 39: 366-73.

Goldman, L., Rockwell, R. J. Jr, Meyer, R. \& Otten, R. (1968). "Investigative Studies with the Laser in the Treatment of Basal Cell Epitheliomas," Southern Medical Journal; 61: 735-42.

Goldman, L. \& Wilson, R. G. (1964). "Treatment of Basal Cell Epithelioma by Laser Radiation," JAMA; 189: 773-5. 
Horlock, N., Grobbelaar, A. O. \& Gault, D. T. (2000). "Can the Carbon Dioxide Laser Completely Ablate Basal Cell Carcinomas? A Histologic Study," British Journal of Plastic Surgery; 53: 286-93.

Humpreys, T. R., Malhotra, R., Scharf, M. J., Marcus, S. M., Starkus, L. \& Calegari, K. (1998). "Treatment of Superficial Basal Cell Carcinoma and Squamous Cell Carcinoma in Situ with a High-Energy Pulsed Carbon Dioxide Laser," Archives of Dermatology; 134: 1247-52.

Ibrahimi, O. A., Sakamoto, F. H., Tannous, Z. \& Anderson, R. R. (2011). “755 nm Alexandrite Laser for the Reduction of Tumor Burden in Basal Cell Nevus Syndrome," Lasers in Surgery and Medicine; 43: 68-71.

Iyer, S., Bowes, L., Kricorian, G., Friedli, A. \& Fitzpatrick, R. E. (2004). "Treatment of Basal Cell Carcinoma with the Pulsed Carbon Dioxide Laser: A Retrospective Analysis," Dermatologic Surgery; 30: 12141218.

Jung, D.- S., Cho, H.- H., Ko, H.- C., Bae, Y.- C., Oh, C.- K., Kim, M.- B. \& Kwon, K.- S. (2011). "Recurrent Basal Cell Carcinoma Following Ablative Laser Procedures," Journal of the American Academy of Dermatology; 64: 723-9.

Kagy, M. K. \& Amonette, R. (2000). "The Use of Imiquimod 5\% Cream for the Treatment of Superficial Basal Cell Carcinomas in a Basal Cell Nevus Syndrome Patient," Dermatologic Surgery; 26: 577-579.

Kokoszka, A. \& Scheinfeld, N. (2003). "Evidence-Based Review of the Use of Cryosurgery in Treatment of Basal Cell Carcinoma," Dermatologic Surgery; 29: 566-71.

Konnikov, N., Avram, M., Jarell, A. \& Tannous, Z. (2011). "Pulsed Dye Laser as a Novel Non-Surgical Treatment for Basal Cell Carcinomas: Response and Follow up 12-21 Months after Treatment," Lasers in Surgery and Medicine; 43: 72-8.
Krunic, A. L., Viehman, G. E., Madani, S. \& Clark, R. E. (1998). "Microscopically Controlled Surgical Excision Combined with Ultrapulse $\mathrm{CO} 2$ Vaporization in the Management of a Patient with the Nevoid Basal Cell Carcinoma," The Journal of Dermatology; 25: 10-2.

Lo, J. S., Snow, S. N., Reizner, G. T., et al (1991). "Metastatic Basal Cell Carcinoma: Report of Twelve Cases with a Review of the Literature," Journal of the American Academy of Dermatology; 24: 715-19.

Mallon, E. \& Dawber, R. (1966). "Cryosurgery in the Treatment of Basal Cell Carcinoma. Assessment of One and Two Freeze-Thaw Cycle Schedules," Dermatology Surgery; 22: 854-8.

McGuff, P. E. (1966). "Laser Radiation for Basal Cell Carcinoma," Dermatologica; 133: 379-83.

Moskalik, K., Kozlov, A., Demin, E. \& Boiko, E. (2009). "The Efficacy of Facial Skin Cancer Treatment with High-Energy Pulsed Neodymium and Nd: YAG Lasers," Photomedicine and Laser Surgery; 27: 3459.

Nouri, K., Chang, A., Trent, J. T. \& Jimenez, G. P. (2002). "Ultrapulse CO2 Used for the Successful Treatment of Basal Cell Carcinomas Found in Patients with Basal Cell Nevus Syndrome," Dermatologic Surgery; 28:287-90.

Robinson, J. K., Hernandez, C., Anderson, E. R. \& Nickoloff, B. (2003). "Topical and Light-Based Treatments for Basal Cell Carcinoma," Seminars in Cutaneous Medicine and Surgery; 22: 171-6.

Rowe, D. E., Carroll, R. J. \& Day, C. L. (1989). "Mohs Surgery is the Treatment of Choice for Recurrent (Previously Treated) Basal Cell Carcinoma," The Journal of Dermatologic Surgery and Oncology; 15: 424-31. 
Schulze, H. J., Cribier, B., Requena, L., et al (2005). "Imiquimod 5\% Cream for the Treatment of Superficial Basal Cell Carcinoma: Results from a Randomized Vehicle-Controlled Phase III Study in Europe," British Journal of Dermatology; 152: 939-47.

Shah, S. M., Konnikov, N., Duncan, L. M. \& Tannous, Z. S. (2009). "The Effect of 595 $n m$ Pulsed Dye Laser on Superficial and Nodular Basal Cell Carcinomas," Lasers in Surgery and Medicine; 41: 417-22.

Smucler, R. \& Vlk, M. (2008). “Combination of Er: YAG Laser and Photodynamic Therapy in the Treatment of Nodular Basal Cell Carcinoma," Lasers in Surgery and Medicine; 40: 153-8.

Spiller, W. F. \& Spiller, R. F. (1984). "Treatment of Basal Cell Epitheliomas by Curretage and Electrodessication," Journal of the American Academy of Dermatology; 11: 808-814.

Star, W. M., Van't Veen, A. J., Robinson, D. J., Munte, K., de Haas, E. R. \& Sterenborg, H. J. (2006). "Topical 5-Aminolevulinic Acid Mediated Photodynamic Therapy of Superficial Basal Cell Carcinoma Using Two Light Fractions with a Two-Hour Interval: Long-Term Follow-up," Acta Dermato Venereologica; 86: 412-7.

Telfer, N. R., Colver, G. B. \& Morton, C. A. (2008). "Guidelines for the Treatment of Basal Cell Carcinoma," British Journal of Dermatology; 159: 35-48.

Van der Geer, S., Ostertag, J. U. \& Krekels, G. A. (2009). "Treatment of Basal Cell Carcinomas in Patients with Nevoid Basal Cell Carcinoma Syndrome," Journal of the European Academy of Dermatology and Venereology; 23: 308-13.

Walker, P. \& Hill, D. (2006). "Surgical Treatment of Basal Cell Carcinomas Using Standard Postoperative Histological Assessment," Australasian Journal of Dermatology; 47: 1-12.
Wheeland, R. G., Bailin, P. L., Ratz, J. L. \& Roenigk, R. K. (1987). "Carbon Dioxide Laser Vaporization and Curettage in the Treatment of Large or Multiple Superficial Basal Cell Carcinomas," TheJournal Dermatologic Surgery and Oncology; 13: 119-25. 